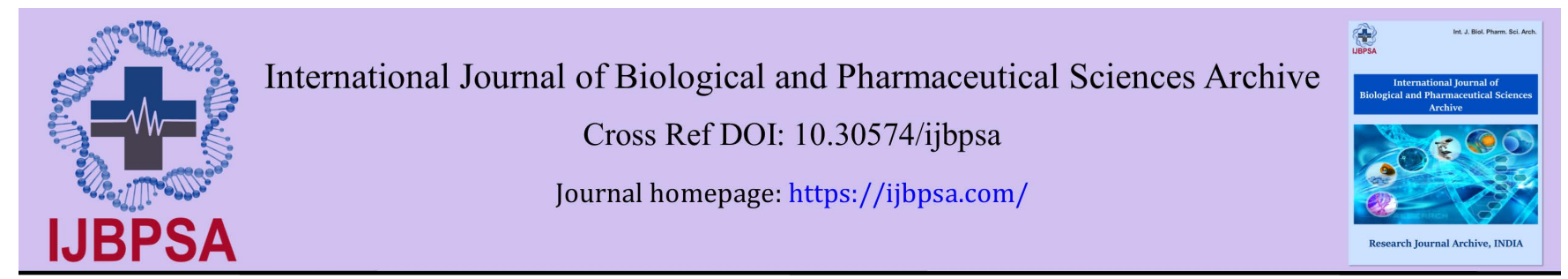

(REVIEW ARTICLE)

\title{
The medical importance of Iris pallida - A review
}

\author{
Ali Esmail Al-Snafi * \\ Department of Pharmacology, College of Medicine, University of Thi-Qar, Iraq.
}

International Journal of Biological and Pharmaceutical Sciences Archive, 2021, 01(02), 190-196

Publication history: Received on 22 April 2021; revised on 25 May 2021; accepted on 28 May 2021

Article DOI: https://doi.org/10.30574/ijbpsa.2021.1.2.0046

\begin{abstract}
Iris pallid (Family: Iridaceae) was used traditionally asantispasmodic, aperient, aromatic, attenuant, carminative, detoxicant, diuretic, emetic, emmenagogue, expectorant, fixative, laxative, pectoral, purgative and sedative. It contained oils and aromatic constituents, fat, resin, a large quantity of starch, mucilage, phenolics, flavonoids and glucosides. Iris pallida possessed many pharmacological effects included anti-inflammatory, antioxidant, anti-aging, anticancer, antiparasitic and antimicrobial activities. The current review will highlight the chemical constituents and pharmacological effects of Iris pallida.
\end{abstract}

Keywords: Constituents; Pharmacology; Inflammatory; Antioxidant; Anti-aging; Iris pallida

\section{Introduction}

Plants generally produce many secondary metabolites which are bio-synthetically derived from primary metabolites and constitute an important source of chemicals which are used as pharmaceuticals, agrochemicals, flavours, fragrances, colours, biopesticides and food additives. Recent reviews showed that the medicinal plants possessed wide range of biological effects included central nervous, cardiovascular, antioxidant, endocrine and reproductive, gastro-intestinal, respiratory, antidiabetic, antimicrobial, antiparasitic, dermatological, anticancer, anti-inflammatory, antipyretic, analgesic, immunological and many other pharmacological effects[1-15]. Iris pallid (Family: Iridaceae) was used traditionally as antispasmodic, aperient, aromatic, attenuant, carminative, detoxicant, diuretic, emetic, emmenagogue, expectorant, fixative, laxative, pectoral, purgative andsedative. It contained oils and aromatic constituents, fat, resin, a large quantity of starch, mucilage, phenolics, flavonoids and glucosides. Iris pallida possessed many pharmacological effects included anti-inflammatory, antioxidant, anti-aging, anticancer, antiparasitic and antimicrobial activities. The current review discussed the chemical constituents and pharmacological effects ofIris pallida.

\section{Plant profile}

\subsection{Synonyms}

Iris australis var. mandraliscae, Iris australis var. tinaei, Iris fulgida, Iris germanica subsp. pallida, Iris glauca, Iris gloriosa, Iris hortensis, Iris mandraliscae, Iris marchesettii, Iris moggridgei, Iris odoratissima, Iris pallida subsp. mandraliscae, Iris pallidavar. odoratissima, Iris pallida subsp. pallida, Iris pallida var. rosea, Iris pallida subsp. sicula, Iris pallida subsp. tinaei, Iris pallida ecaerulaea, Iris plicata, Iris propendens, Iris sicula, Iris swertii, Iris tinaei, Iris pallida subsp. cengialti, Iris pallida subsp. illyrica [16].

${ }^{*}$ Corresponding author: Ali Esmail Al-Snafi

Department of Pharmacology, College of Medicine, University of Thi-Qar,Iraq.

Copyright (c) 2021 Author(s) retain the copyright of this article. This article is published under the terms of the Creative Commons Attribution Liscense 4.0. 


\subsection{Taxonomic classification}

Kingdom: Plantae;

Subkingdom: Viridiplantae;

Infrakingdom: Streptophyta;

Superdivision: Embryophyta;

Division: Tracheophyta;

Subdivision: Spermatophytina;

Class: Magnoliopsida;

Superorder: Lilianae;

Order: Asparagales;

Family: Iridaceae;

Genus: Iris;

Species: Iris pallida[17].

\subsection{Common names:}

The common word (iris) that gave the name of the genus, originated from Greek designating "rainbow" presumably due to the wide variety of colors that these flowers can have. However, the common names ofIris pallida were:

Arabic: Sausan, Sausan flurancy;

English: Dalmatian iris, fragrant-root iris, orris, sweet iris;

French: iris pâle;

German: bleiche Schwertlilie;

Portuguese: íris;

Spanish: lirio pálido;

Swedish: silveriris [18-20].

\section{Distribution}

It is native to Dalmatian coast, However, it was distributed in Europe (Former Yugoslavia, Italy, Albania, Bulgaria, Romania, France); Asia-temperate (Lebanon, Iraq, Palestine), Africa (Canary Islands) and Northern America (USA)[19, 21].

\subsection{Description}

Stems 1-3-branched, 6-10 dm. Rhizomes branching, forming extensive clumps, 1.5-2 cm diam. The leaves are bluishgreen in color, and sword-shaped, 40-50 cm (16-20 in) in length, and 2.5-3 cm (0.98-1.18 in) in width. Inflorescences with terminal unit 3-flowered, branch units 2-3-flowered; distal branches subtended by scarious bracts, lower one to $15 \mathrm{~cm}$, herbaceous, green; spathes completely silvery white, 2-3.5 cm, scarious. Flowers often very fragrant; perianth light blue-violet to mauve-purple, one form with blue pigment limited as stipples or stitches along margin and/or along veins, with ground color white on both petals and sepals; floral tube 1-1.3 cm; sepals slightly reflexed, obovate, 7.8-8.3 $\times 5-5.3 \mathrm{~cm}$, with wedge-shaped claw marked with brown veins, beard yellow with white tips; petals blue-violet, in some forms lighter than sepals, with some brown veining at base and on claw, obovate, $8 \times 5 \mathrm{~cm}$; ovary trigonal, 6-grooved, 1-1.5 cm; style violet, fading paler along margins, keeled along midrib, $2-2.4 \times 1 \mathrm{~cm}$, crests rounded, $1.4 \mathrm{~cm}$, apex acute; stigmas rounded, margins entire; pedicel very short, $2-3 \mathrm{~mm}$. Capsules borne on ends of stems and branches, oblong, trigonal, 6-grooved, 4-5 × 1.5-2 cm. Seeds in 2 rows per locule, dark brown, compressed, cubical, wrinkled [21-23].

\subsection{Traditional uses}

The root wasused as antispasmodic, aperient, aromatic, attenuant, carminative, detoxicant, diuretic, emetic, emmenagogue, expectorant, fixative, laxative, pectoral, purgative andsedative [24].

The peeled and dried rhizomes of Iris germanica as well as its variety florentina and Iris pallidawere known as orris root or as rhizoma iridis and were used for centuries in medicinal treatments, while today they are most important particularly for production of orris butter[25]. Rhizomes of Iris pallida (orris root) were used in perfume and medicine. The juice of the fresh root is a strong purge of great efficiency in the treatment of dropsy. Orris oilderived from the dried root, was used as a flavouring in soft drinks, sweets, chewing gum etc. It was much used as a fixative in perfumery, as an ingredient of toothpastes, for the treatment of coughandas breath fresheners [21, 24-26].

Parts used: Rhizomes with the roots and oil [24, 27]. 


\subsection{Chemical constituents}

The chief constituent of the root was the Oil of Orris, also known as Orris Butter, which constitutes about 0.1 to 0.2 percent of the dried root; it is a yellowish white, semisolid mass. Other constituents of Orris root were fat, resin, a large quantity of starch, mucilage, a bitter principle and a glucoside named Iridin. The aromatic constituent of Orris root was irone, which gives the dried, aged root its characteristic violet like odor [28-30].

The essential oils obtained from the leaves and rhizomes of Iris pallida from Ukraine were $0.03 \%$ and $0.20 \%$, respectively. 26 components were identifiedin the leaves and 18 in the rhizomes. The major terpenes in the essential oil of the leaves were squalene (6\%), hexahydrofarnesylacetone (8\%) and neophytadiene (up to 6\%). Among them, myristic acid (56\%), capric acid (14.50\%), lauric acid (15.42\%), $\alpha$-irone $(2.85 \%)$ were found as the major constituents of the essential oil of the rhizomes of I. pallida. $\alpha$-irone and $\gamma$-irone contents are accepted as the most significant criteria of the commercial quality of Iris essential oil [26].

Quantitative analysis of the phenolic compounds of I. pallida revealed that it contained gallic acid2.362 \pm 0.076 , mangiferin $0.849 \pm 0.029$, caffeic acid $0.227 \pm 0.033$, tectoridin $1.642 \pm 0.023$,germanaism B $0.534 \pm$ 0.015 , irisolidone-D- glucoside $0.325 \pm 0.030$, iristectorigenin B $0.354 \pm 0.004$, nigricin $0.317 \pm 0.003$, irigenin $3.199 \pm$ $0.034,5,6$-dihydroxy-7,8, $3^{\prime}, 5^{\prime}$ - tetramethoxy isoflavone $0.457 \pm 0.003$ and irisolidone $0.264 \pm 0.004 \mathrm{mg} / \mathrm{g}$ [31].

The highest number of (iso)flavonoids was detected in I. pallida leaves and roots, which consisted of 35 and 38 (iso)flavonoids, respectively, while less than half of them were detected in the rhizomes of this species [32].

Iris pallida rhizomes wasrich in flavonoids (resinoids of I. pallida rhizomes contained $120 \pm 3.3 \mathrm{mg} / \mathrm{g}$ isoflavones). One isoflavanone (2,3-dihydroirigenin) and one benzophenone (2,6,4'-trihydroxy-4-methoxybenzophenone) only were identified in I. pallida resinoid[33]. However, Isoflavones isolated from different parts of Iris pallida were included: iristectorigenin A, irisflorentin, irilone, irigenin, 8-hydroxyirigenin, nigricin, nigricanin, iris kumaonin methyl ether, irisflogenin and 2,3-dihydroirigenin [34]. 0.1-0.7 \% of iridals and their esters were extracted from the leaves of I. pallida [35].

However, the ironecontents ofIris pallida was $1386 \mathrm{mg} / \mathrm{kg}$ dry mass, and $866 \mathrm{~g} / \mathrm{plant}$ in fress mass. Four irone isomers (Trans- $\alpha$, cis- $\alpha$, cis- $\gamma$ and $\beta$ - irone) were identified in Iris pallida [36].

The average composition of the irone oil produced by the enzymatic method employed on four batches of fresh Iris pallida rhizomes: $4 \%$ of $(+)$-trans- $\alpha$-irone, $0.6 \%$ of $(-)$-trans- $\gamma$-irone, $31.6 \%$ of predominantly dextrorotatory cis- $\alpha-$ irone, $49.8 \%$ of $(+)$-cis- $\gamma$-irone, traces of $\beta$-irone, and $13.8 \%$ of other unidentified components [37].

The isomeric ironesin Iris pallidawere developedon oxidative cleavage of the methylated triterpenoids iripallidal or its isomer iriflorental. Their possible precursor was the squalene is the C 30-compound isoiridogermanal which was found in rhizomes of Iris pallida [38].

Methionine was readily incorporated into cycloiridals of Iris pallida dalmatica, thus indicating that the methylation of iridals via S-adenosyl- L - methionine led to the formation of the irone moiety of the bicyclic compounds. The cycloiridals, C31-triterpenoids, also served as precursors of the irones [39].

To increase the production of a mixture enriched in cis- $\gamma$-irone,the iris rhizomes, parts of these rhizomes, iris extracts, or iris wastes were incubated with two bacterial strains, in the presence of a plant cell culture medium (Serratia liquefaciens and Pseudomonas maltophilia).Incubation of Iris pallida rhizomes with these strains increased theproduction of irones. After eight days, irone content reached $1 \mathrm{~g}$ per kg of dry rhizome, whereas only $400 \mathrm{mg}$ per $\mathrm{kg}$ were obtained by the traditional procedure using rhizomes stored for three years $[37,40]$.

\section{Pharmacological effects}

\subsection{Anti-aging and dermatological effects}

Sweet iris acts on consequences of natural aging at the conjunctive level of the dermis and the upper layer of the epidermis, at the level of the dermis, the sweet iris stimulates the synthesis of constituents of the extra-cell matrix collagens, glycosaminoglycans, elastin and proteoglycans - while limiting the action of the enzyme that destroys them. In the same time, it helps to regenerate the epidermis in a well-balanced way by increasing the production and the differentiation of the cells of the epidermis that slows down with ageing. Skin layers can get back their density and their 
global balance, which limit the creation of wrinkles. Anti-wrinkle effect of sweet iris was evaluated in women after 28 days of treatment (face): it decrease of the total surface by $24 \%$, decrease of the number of wrinkles by $19 \%$ and decrease of the length of wrinkles by $26 \% .80 \%$ of women declared that their wrinkles seem to have decreased [41].

\subsection{Anti-inflammatory and antioxidant effects}

The respiratory burst and degranulation of neutrophils are important processes in the maintenance of human health, but they need careful regulation to prevent the development of chronic and auto-immune diseases. Superoxide is a major radical produced by neutrophils and its excessive amount contributes to several acute and chronic diseases, including lung injury, sepsis, or arthritis. The effects of Iris extracts on superoxide anion generation and elastase release triggered by fMLF in CB-primed human neutrophils were studied. The results revealed that the water extracts Iris rhizomes showed anti-inflammatory potential and inhibited superoxide anion generation at $10 \mu \mathrm{g} / \mathrm{ml} \mathrm{by} 41.0-45.7 \%$. Both the ethanolic and water extracts of the rhizomes showed enhancing effects on elastase release by human neutrophils and thus may have immune-promoting effects related to degranulation [31].

\subsection{Cytotoxic effects}

A bicyclic triterpenoid isolated possessed anti-proliferative activity in the NCI 60 Human Cancer Cell Lines with GI50 concentrations ranging from micromolar to nanomolar range. Binds to PKC $\alpha$ with high affinity $(\mathrm{Ki}=75.6 \mathrm{nM})$. Also binds to RasGRP3 (Ki = $15.5 \mathrm{nM}$ ), a phorbol ester receptor that links DAG/phorbol ester signaling with Ras activation. Binding is competitive with respect to phorbol ester. Itinduced translocation of RasGRP3 from the cytoplasm to fibrillar structures and the nuclear membrane. Also induced phosphorylation of ERK1/2 in a RasGRP3-dependent manner [4243].

Six different triterpenoids (iridals) were bioassayed on two cultured human tumor cell lines: A2780 and K562 (and for each one a drug-sensitive and a drug-resistant cell line). All of the tested iridals had an IC 50 in the 0.1 to $5.3 \mathrm{microg} / \mathrm{ml}$ range. Some of them were shown to be more effective than doxorubicine [44]. Iridal, a triterpenoidic compound showed anticancer activity against two cultured human tumor cell lines (A2780 and K562) [45].

Eleven iridal type triterpenoids were examined for protein kinase C (PKC) activation and binding activity to PKC. Nine iridals showed dose-dependent activities, and a mutual relation between the two activities was also observed. The structural requirements of the iridals for these activities included (i)a hydrophobic side-chain, (ii)an E-methylidene aldehyde group at the $\mathrm{C}-1$ position, and (iii)a hydroxyl group at the C-26 position [46].

However, the extracts were evaluated for their in vitro cytotoxicity in human fibroblasts usingresazurin assay after 72 $\mathrm{h}$ of exposure. No toxicity was observed for fibroblasts (MRC cell line) at the highest tested concentration (670 mg/l) [32].

\subsection{Antiparasitic effects}

Iridal, a triterpenoidic compound was tested in vitro on Plasmodium falciparum chloroquine-resistant and -sensitive strains and in vivo on $P$. vinckei. The IC50 obtained in vitro on human malaria strain was ranged from 1.8 to 26.0 $\mathrm{microg} / \mathrm{ml}$ and the ED 50 in vivo was $85 \mathrm{mg} / \mathrm{kg} /$ day by intraperitoneal route [45].

Iridalsalso showed antitrypanosomal activity with the using of in vitro screening assays [47].

\subsection{Antimicrobial effects}

The antibiofilm activity of 15 methanolic extracts of Iris species was investigated against both mono-(Pseudomonas aeruginosa, Staphylococcus aureus) and multi-species oral biofilms (Streptococcus gordonii, Veillonella parvula, Fusobacterium nucleatum subsp. nucleatum, and Actinomyces naeslundii). Among Iris species, I. pallida, inhibited both the quorum sensing and adhesion during biofilm formation in a concentration-dependent manner. However, the extracts were less active against maturated biofilms. The inhibition of bacterial adhesion significantly correlated with myristic acid content, and quorum sensing inhibition correlated with the 7-_-hydroxystigmast-4-en-3-one content [32].

Iridal, a triterpenoidic compound was tested against Candida albicans and C. parapsilosis strains. The minimal antifungal inhibitory concentrations were higher than to $50 \mathrm{microg} / \mathrm{ml}$, whatever the strain of yeast tested [45]. 


\section{Conclusion}

This review discusses the traditional uses, chemical constituent, pharmacological and therapeutic effects of Iris pallid as promising herbal drug because of its safety and effectiveness.

\section{Compliance with ethical standards}

\section{Acknowledgments}

We acknowledged the dean of Thi Qar College of medicine for the scientific support.

\section{References}

[1] Al-Snafi AE. Oils and fats contents of medicinal plants, as natural ingredients for many therapeutic purposes- A review. IOSR Journal of Pharmacy. 2020; 10(7): 1-41.

[2] Al-Snafi AE. Phenolics and flavonoids contents of medicinal plants, as natural ingredients for many therapeutic purposes- A review. IOSR Journal of Pharmacy. 2020; 10(7): 42-81.

[3] Al-Snafi AE. Medical benefit of Lallemantia iberica- A review. To Chemistry Journal. 2019; 3: 128-133.

[4] Al-Snafi AE. A review on Lawsonia inermis: A potential medicinal plant. International Journal of Current Pharmaceutical Research. 2019; 11(5):1-13.

[5] Al-Snafi AE. Chemical constituents and pharmacological effects of Melilotus Officinalis- A review. IOSR Journal of Pharmacy. 2020; 10(1):26-36.

[6] Al-Snafi AE.Bioactive metabolites and pharmacology of Cistanche tubulosa- A review.IOSR Journal of Pharmacy. 2020; 10(1): 37-46.

[7] Al-Snafi AE. Pharmacological potential of Orchis mascula- A review. IOSR Journal of Pharmacy. 2020;10(3):1-6.

[8] Al-Snafi AE. Constituents and pharmacology of Onopordum acanthium. IOSR Journal of Pharmacy. 2020; 10(3):714.

[9] Al-Snafi AE.The traditional uses, constituents and pharmacological effects of Ononis spinosa. IOSR Journal of Pharmacy. 2020; 10(2):53-59.

[10] Al-Snafi AE. Al-Saedy HA, Talab TA, Majid WJ, El-Saber Batiha G, Jafari-Sales Abolfazl. The bioactive ingredients and therapeutic effects of Marrubium vulgare - A review. International Journal of Biological and Pharmaceutical Sciences Archive. 2021; 1(2):9-21.

[11] Al-Snafi AE. Khadem HS, Al-Saedy HA, Alqahtani AM, El-Saber Batiha G. Jafari-Sales Abolfazl.A review on Medicago sativa: A potential medicinal plant. International Journal of Biological and Pharmaceutical Sciences Archive. 2021; 1(2):22-33.

[12] Al-Snafi AE.Talab TA, Jabbar WM, Alqahtani AM. Chemical constituents and pharmacological activities of Mirabilis jalapa-A review. International Journal of Biological and Pharmaceutical Sciences Archive. 2021; 1(2):34-45.

[13] Al-Snafi AE. Medicinal plants alkaloids, as promising therapeutics- A review (part 1). IOSR Journal of Pharmacy. 2021; 11(2): 51-67.

[14] Al-Snafi AE. Chemical constituents and pharmacological effects of Ocimum basilicum- A review. International Journal of Pharmaceutical Research. 2021; 13(2): 2997-3013.

[15] Al-Snafi AE, Ibraheemi ZAM, Talab TA. A review on components and pharmacology of Mangifera indica. International Journal of Pharmaceutical Research. 2021; 13(2): 3043- 3066.

[16] The plant list, Iris pallida. Available: The plant list, Iris pallida. http://www.theplantlist.org/ tp11.1/record/kew-322201

[17] ITIS, Iris pallida. Available: https:// www.itis.gov/servlet/SingleRpt/Single Rpt?search _ topic= TSN\& search_ value $=43223 \#$ null.

[18] Cumo C (ed). Encyclopedia of Cultivated Plants: From Acacia to Zinnia, ABC-CLIO, Santa Barbara, California USA. 2013; 1:532-533. 
[19] US National plant germplasm system,Iris pallida Lam. Available: https://npgsweb.ars-grin.gov/ gringlobal/ taxonomydetail.aspx?20378

[20] Missouri Botanical Garden, Iris pallida. Available: http://www.missouribotan icalgarden.org/ Plant Finder Plant Finder Details. aspx?kempercode=a7 95.

[21] Ioana C, Maria C. New rerspectives on medicinal properties and uses of iris sp. Hop and Medicinal Plants. 2016; 14(1-2): 24-36.

[22] Flora ofNorth America, Iris pallida. Available: http://www.efloras.org/florataxon.aspx? flora_id $=1 \&$ taxon_id $=200028194$

[23] iNaturalist.org, Sweet Iris (Iris pallida). Available: http://www.inaturalist.org/taxa/ 164131-Iris-pallida

[24] Edible and Medicinal Plants, Iris pallida. Available: http://plants.for9.net/edible-and-medicinal-plants/

[25] Al-Snafi AE. Encyclopedia of chemical constituents and pharmacological effects of Iraqi medicinal plants. Rigi Publication, India 2015.

[26] Mykhailenko 0. Composition of volatile oil of Iris pallida Lam. from Ukraine. Turk J Pharm Sci. Apr 2018; 15(1): 85-90.

[27] Almaarri K, Abou Zedan T, Albatal N. Chemical Analysis of essential oils of some Syrian wild Iris species. American Journal of Biochemistry and Molecular Biology. 2013; 3: 38-49.

[28] Greek medicine. net , Iris root, Available: http:// www. greekmedicine. net/A_ Greek_ and_ Unani_ Herbal/herb.php?id=15

[29] Herbs2000.com,Orris root, Iris pallida, A practical guide for nutritional and traditional health care.

[30] Botanical.com, Irises. Available: http:// www. botanical. com/ botanical/ mgmh/i/ irises08.html

[31] Mykhailenko O, Korinek M, Ivanauskas L, Bezruk I, Myhal A, Petrikaitė V, El-Shazly M, Lin GH, Lin CY, Yen CH, Chen BH, Georgiyants V, Hwang TL. Qualitative and quantitative analysis of Ukrainian Iris species: A fresh look on their antioxidant content and biological activities. Molecules. 2020; 25(19): 4588.

[32] Hoang L, Beneš F, Fenclová M, Kronusová O, Švarcová V, Řehořová K, Švecová EB, Vosátka M, Hajšlová J, Kaštánek P, Viktorová J, Ruml T. Phytochemical composition and in vitro biological activity of Iris spp. (Iridaceae): A new source of bioactive constituents for the inhibition of oral bacterial biofilms. Antibiotics (Basel). 2020; 9(7): 403.

[33] Roger B, Jeannot V, Fernandez X, Cerantola S, Chahboun J. Characterisationand quantification of flavonoids in Iris germanica L. and Iris pallida Lam. resinoids from Morocco.Phytochem Anal. 2012; 23(5): 450-455.

[34] Kukula-Koch W, Sieniawska E, Widelski J,Urjin O,Głowniak P, Skalicka-Woz'niak K. Major secondary metabolites of Iris spp. Phytochem Rev. 2015; 14: 51-80.

[35] Marner FJ, Kerp B. Composition of iridals, unusual triterpenoids from sword-lilies, and the seasonal dependence of their content in various parts of different Iris species. Z Naturforsch C. 1992; 47(1-2): 21-25.

[36] Firmin L, Courtois D, Petiard V. Evaluation of the natural variability in irone content and selection of iris sp for perfume production. Hort Sci. 1998; 33(6): 1046-1047.

[37] Brenna E, Fuganti C, SerranoS. Applications of biocatalysis in fragrance chemistry: the enantiomers of $\alpha-, \beta$-, and $\gamma$-irones. Chem Soc Rev. 2008; 37: 2443-2451.

[38] Krick W, Marner FJ, Jaenicke L. Isolation and structural determination of a new methylated triterpenoid from rhizomes of Iris versicolor L. Z Naturforsch 1983; 38c: 689 -692.

[39] Marner FJ, Runge T, König WA. Separation of enantiomeric irones by gas-liquid chromatography on modifi ed cyclodextrins. Helv Chim Acta. 1990; 73: 2165-2170.

[40] Belcour B, Courtois D, Petiard V. Rapid production of irones by maturation of orris rhizomes with two bacterial strains. Phytochemistry. 1993; 34(5): 1313-1315.

[41] Technical information formulating All Even Sweet iris, Iris pallida. All Even Sweet iris increasing skin density.

[42] Calbiochem, Iripallidal, Iris pallida. Available: http://search.cosmobio.co.jp/cosmo_ search_p/search_gate2/ docs/CBC_/412500.20040716.pdf

[43] Shao L, Lewin NE, Lorenzo, et al. Iridals are a novel class of ligands for phorbol ester receptors with modest selectivity for the RasGRP receptor subfamily.J Med Chem 2001; 44 (23); 3872-3880 
[44] Bonfils JP, Pinguet F, Culine S, Sauvaire Y. Cytotoxicity of iridals, triterpenoids from Iris, on human tumor cell lines A2780 and K562. Planta Med. 2001; 67(1): 79-81.

[45] Benoit-Vical F, Imbert C, Bonfils JP, Sauvaire Y. Antiplasmodial and antifungal activities of iridal, a plant triterpenoid. Phytochemistry.2003; 62(5): 747-751.

[46] Takahash K, Suzuki S, Hano Y, Nomura T. Protein kinase C activation by iridal type triterpenoids. Biological \& Pharmaceutical Bulletin. 2002; 25(4): 432-436.

[47] Pathiranage AL. Isolation and analysis of compounds with antitrypanosomal and anti- cancer activity. PhD thesis, Middle Tennessee State University, 2016. 